\title{
Continuous Production of Water-Based UV-Curable Polyurethane Dispersions Using Static Mixers and a Rotor-Stator Mixer
}

\author{
Sven R. L. Gobert, ${ }^{\dagger}$ Arne Vancleef, ${ }^{*}{ }^{\dagger}$ Seppe Clercx, Leen Braeken, and Leen C. J. Thomassen* \\ Cite This: https://doi.org/10.1021/acsomega.1c01525 \\ Read Online
}

ABSTRACT: UV-curable polyurethane dispersions (UV-PUDs) have applications in coatings for a variety of materials. Historically, the neutralization and dispersion steps of the UV-PUD production process have been performed in batch. However, continuous processing might reduce capital and operating costs, improve the dispersion characteristics, and facilitate scale-up. Static mixers and inline high-shear mixers are able to provide the necessary shear forces to obtain miniemulsions. The production of a UV-PUD is therefore studied in a continuous setup, whereby the neutralization step is performed in static mixers and the dispersion step is performed either in static mixers or in a high-shear mixer. The influence of the prepolymer temperature, mixing energy, and feed

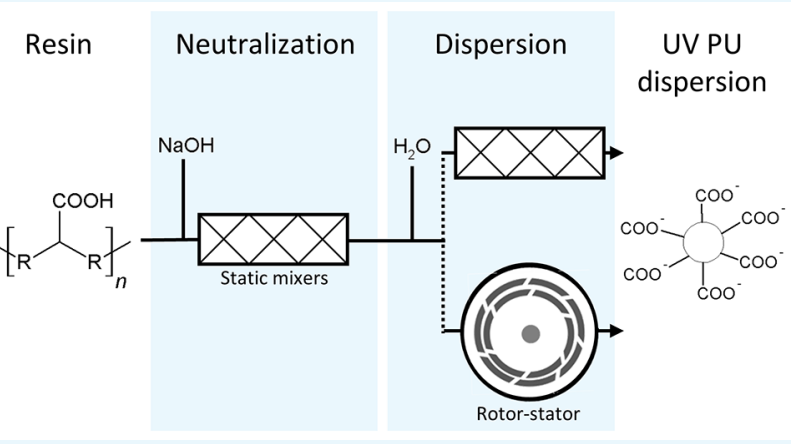
flow rate on the particle size and stability of the UV-PUD particles in water is explored. The results show that the neutralization step is mixing-sensitive, and the temperature of the neutralized prepolymer influences the particle size in the dispersion process. The amount of shear force applied during the dispersion step has a limited effect on the particle size. UV-PU dispersions with an average particle size below $80 \mathrm{~nm}$ and PDI below 0.1 are obtained with static mixers or in an inline rotor-stator mixer, at flow rates of 5.2 and $7.2 \mathrm{~L} / \mathrm{h}$, respectively. This research demonstrates that continuous processing using static mixers and high-shear mixing is a viable option for the neutralization and dispersion of UV-PUDs.

\section{INTRODUCTION}

Water-based polyurethane (PU) coatings have been on the market for over 50 years and continue to gain interest with increased governmental restrictions on the use of volatile organic solvents. ${ }^{1,2}$ They have excellent chemical and mechanical properties, including water and solvent resistance, film formation at room temperature, adhesion to a diverse range of substrates and scratch, abrasion, and impact resistance. $^{3}$ These coatings are based on a dispersion of colloidal polyurethane particles in water. UV-curable PUDs typically have additional acrylic groups that are cross-linked using ultraviolet light, whereby a PU film is formed.

Dispersion of polyurethane polymer resins and UV-curable PU polymer resins in water is made possible by either emulsifiers and/or ensuring the presence of hydrophilic structures along the polymer chain. ${ }^{4,5}$ These hydrophilic structures are typically carboxylate groups that are ionized during the neutralization reaction. The degree of hydrophilicity will influence the emulsification process, whereby high hydrophilicity leads to smaller particles. ${ }^{6}$ Large PU particles $(\geq 1 \mu \mathrm{m})$ reduce the shelf life of the coating, as they tend to coagulate and cause irreversible phase separation. ${ }^{1,5}$

Apart from the chemical structure, the droplet size is governed by the applied shear forces, which are provided by impellers, high shear mixers, ultrasonic probes, or static mixers. ${ }^{7}$ For large-scale production, continuous processing becomes an interesting alternative to batch, as batch-to-batch variation is eliminated through continuous steady-state operation, and furthermore, the production cost per unit is reduced. ${ }^{8}$ Continuous processing can also be an effective tool for the production of PUDs, as highlighted in a review by Liu, Hong, and Chen. ${ }^{9}$ A continuous process for PU dispersions has been presented by Keyvani, which involved a two-step process: first neutralization of the prepolymer in a static mixer, followed by the dispersion in water including a chain extender in two Oakes rotor-stator mills in series. ${ }^{6}$ They found that the mode of processing (i.e., batch or continuous) influenced the PU dispersion stability. Their batch setup with a Cowles blade impeller produced unstable PU dispersions with particle sizes exceeding $1 \mu \mathrm{m}$, while the particles were below $1 \mu \mathrm{m}$ for the continuous setup. However, rotor-stator mixers (RSMs) are also expected to have a significantly higher mixing intensity than the batch stirrer; therefore, it is not necessarily the processing mode (batch or continuous) that resulted in the

Received: March 22, 2021 


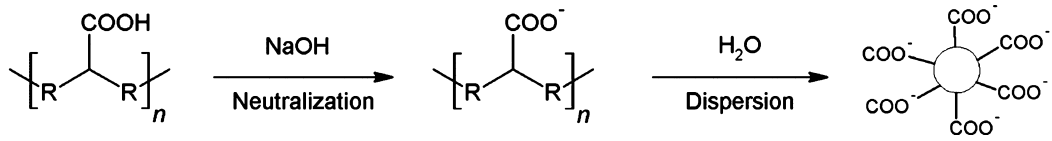

Figure 1. Schematic representation of the neutralization and dispersion step.

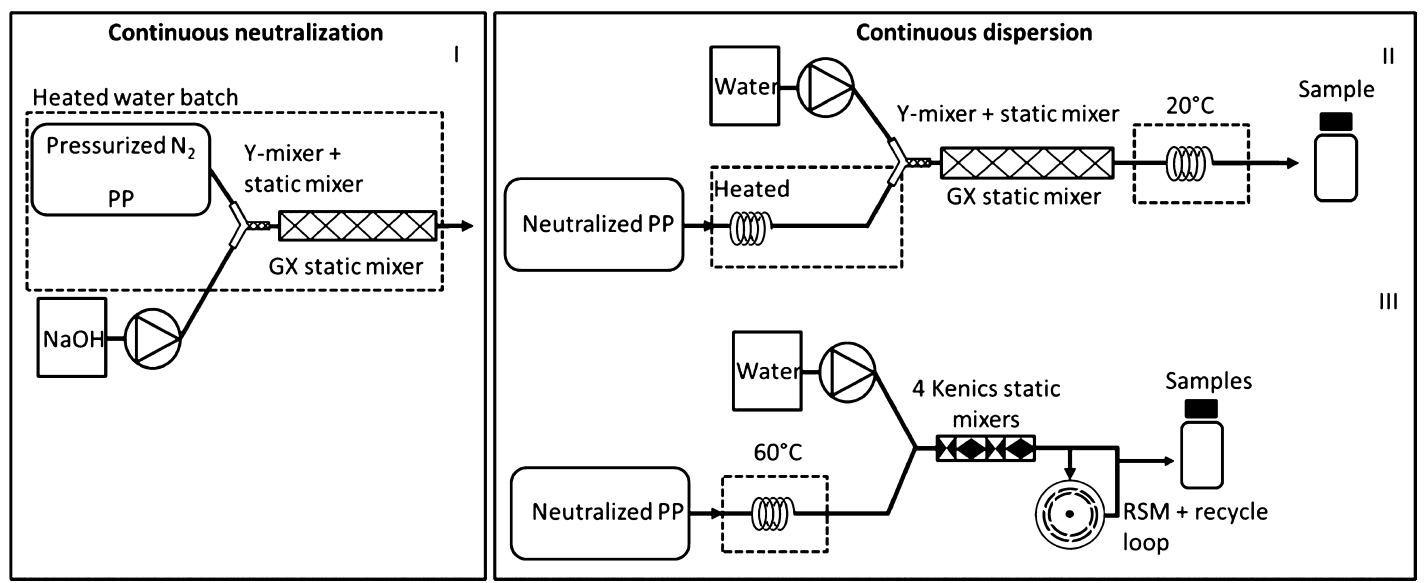

Figure 2. General representation of flow setups for neutralization in static mixers (I) and dispersion in static mixers (II) or in an inline RSM (III).

Table 1. Detailed Overview of Setup Elements and Process Conditions

\begin{tabular}{|c|c|c|c|c|}
\hline $\begin{array}{l}\text { name } \\
\text { setup }\end{array}$ & $\begin{array}{l}\text { neutralization process } \\
\text { setup }\end{array}$ & dispersion process setup & $\begin{array}{l}\text { neutralization temperature/NPP } \\
\text { temperature before dispersion }\left({ }^{\circ} \mathrm{C}\right)\end{array}$ & $\begin{array}{c}\text { total flow rate }(\mathrm{kg} / \mathrm{h}) / \text { corresponding rotational } \\
\text { speed RSM }(\mathrm{rpm}) \text { if applicable }\end{array}$ \\
\hline $1 \mathrm{~A}$ & $\begin{array}{l}\text { flow: open } \\
\quad \text { Y-mixer }+13 \mathrm{GX}\end{array}$ & batch: four-bladed pitched impeller & $50,60,75,80,95 / 75$ & 1.0 \\
\hline $1 \mathrm{~B}$ & $\begin{array}{l}\text { flow: } \\
\text { DDSM-Y-mixer + } 20 \\
\text { GX }\end{array}$ & batch: four-bladed pitched impeller & $75 / 75$ & 1.0 \\
\hline $2 \mathrm{~A}$ & $\begin{array}{l}\text { batch: four-bladed } \\
\text { anchor impeller }\end{array}$ & flow: open Y-mixer $+13 \mathrm{GX}$ & $75 / 40,50,60,70$ & 1.9 \\
\hline $2 \mathrm{~B}$ & $\begin{array}{l}\text { batch: four-bladed } \\
\text { anchor impeller }\end{array}$ & $\begin{array}{l}\text { flow: SMX-Y-mixer + } 13 \mathrm{GX} \text { or } \\
\text { DDSM-Y-mixer + } 13 \mathrm{GX}\end{array}$ & $75 / 50$ & $1.0,2.0,2.5,3.0,3.8,4.5$ \\
\hline $2 \mathrm{C}$ & $\begin{array}{l}\text { batch: four-bladed } \\
\text { anchor impeller }\end{array}$ & flow: RSM MK - RSM G2 & $80 / 100$ & $7.2 / 26,000$ \\
\hline $2 \mathrm{D}$ & $\begin{array}{l}\text { batch: four-bladed } \\
\text { anchor impeller }\end{array}$ & flow: RSM G2 & $75 / 60,75,90$ & $0.6,3.6,7.2 / 7400,15,000,26,000$ \\
\hline $3 \mathrm{~A}$ & $\begin{array}{l}\text { flow: } \\
\text { DDSM-Y-mixer + } 20 \\
\text { GX }\end{array}$ & $\begin{array}{l}\text { flow: SMX-Y-mixer + } 10 \text { SMX }+13 \\
\text { GX }\end{array}$ & $75 / 50$ & $2.4,3.9,5.2$ \\
\hline $3 \mathrm{~B}$ & $\begin{array}{l}\text { flow: } \\
\text { DDSM-Y-mixer + } 20 \\
\text { GX }\end{array}$ & flow: RSM G2 & $75 / 60$ & $7.2 / 15,000$ \\
\hline
\end{tabular}

reduced particle size and increased stability. Phongicaroon, Calabrese, and Carpenter investigated PU dispersions in a batch RSM and showed that the mechanical agitation was mainly responsible for the width of the particle size distribution. ${ }^{4}$ Increasing the rotational speed reduced the width of the distribution but not the mean diameter. The mean particle diameters varied between 8 and $25 \mu \mathrm{m}$. El-Jabi, Cunningham, and McKenna compared an ultrasonic probe, an RSM, and a static mixer for the production of miniemulsions. Regarding the particle size, all three devices produced particles in the range of 100-200 nm. However, these devices differed strongly in energy efficiency and required different mixing times. Static mixers operated with the least energy input, the RSM used the intermediate energy input, and the sonicator used the highest energy input. In this study, the sonicator required only a minute compared to 30-60 min for the static mixer and RSM, respectively, to disperse an equal volume (acrylate monomers and surfactant in water). ${ }^{7}$
To our knowledge, no publications about the continuous neutralization and dispersion of UV-PUDs are available. The objective of this work is to demonstrate the neutralization and dispersion step of UV-curable PU dispersions in a continuous setup and explore the influence of the prepolymer neutralization, prepolymer temperature, rotational speed of the highshear mixer, and flow rate (residence time) during dispersion on the particle size and stability (shelf life) of the UV-PU dispersions. After optimization of the neutralization and dispersion processes, both steps were combined in a single full continuous setup.

\section{MATERIALS AND METHODS}

UV-PU Dispersion Formulation. Polyurethane prepolymer (PP) is provided by Allnex. The carboxyl groups present in the prepolymer are neutralized with a 9 wt $\% \mathrm{NaOH}$ solution to form carboxylate groups, which act as the emulsifier. Neutralization is carried out with a constant ratio 
of 16.4 wt $\% \mathrm{NaOH}$ solution to the prepolymer. For the dispersion step, the neutralized prepolymer (NPP) is mixed with water to provide dispersions with a mass percentage of 35 wt $\%$. Figure 1 visualizes the neutralization and the dispersion process that is used to form the UV-PU dispersions.

Dispersion Characterization. The $\mathrm{Z}$-average particle size and the polydispersity index (PDI) of the UV-PUDs are determined using dynamic light scattering (DLS, Zetasizer Nano, Malvern). The Z-average is the intensity-weighted mean size of the particles, and the PDI is a measure of the width of the size distribution. The samples were diluted in water and measured at $25{ }^{\circ} \mathrm{C}$. Then, the samples are measured three times, with each measurement containing at least 11 submeasurements of which the average is taken.

The zeta potential is also measured using the zetasizer (Zetasizer Nano, Malvern) and gives an indication of the surface charge and thus electrostatic repulsion between particles. In general, dispersions with a zeta potential below $-30 \mathrm{mV}$ have a good stability. ${ }^{10}$ The zeta potential of the different samples is discussed in the text, and data of all measured samples are shown in detail in Supporting Information.

Samples are collected at the reactor exit in threefold in a single run, with at least one residence time in between sample collections. The error bars in the figures below indicate the standard deviation on these three measurements. The stability of the dispersions is tested through an accelerated aging by placing $5 \mathrm{~mL}$ of each sample at $60{ }^{\circ} \mathrm{C}$ for 10 days. Unstable samples clearly display sedimentation of particulate matter after 10 days at $60^{\circ} \mathrm{C}$.

Flow Setups. Figure 2 shows the general configuration of the setups for the continuous neutralization and dispersion. Table 1 accompanies this figure to indicate the experimental conditions and gives a detailed overview of the elements constituting the setups. The influence of the temperature and amount of mixing elements is investigated for the continuous neutralization. The continuous neutralization is studied in setup I, Figure 2, with experimental conditions described in Table 1, experiment numbers $1 \mathrm{~A}$ and $1 \mathrm{~B}$. The dispersion step for these experiments is performed by feeding the NPP at 75 ${ }^{\circ} \mathrm{C}$ from the exit of the flow reactor to a batch reactor with water. Mixing is carried out with a pitched blade impeller (VWR, 441-0374).

The continuous dispersion step is studied in static mixers (experiments $2 \mathrm{~A}$ and $2 \mathrm{~B}$, Table 1 ) or in an inline RSM represented as experiments $2 \mathrm{C}$ and $2 \mathrm{D}$ in Table 1 using setups II and III of Figure 2, respectively. The influence of the NPP temperature, the total flow rate, the static mixers in the Ymixer, and the rotational speed and configuration of the RSM is investigated for the continuous dispersion. In these experiments, the neutralization of the prepolymer is carried out in batch, whereby the batch reactor $(4 \mathrm{~kg})$ is stirred with a four-bladed anchor impellor at $75{ }^{\circ} \mathrm{C}$ and the alkaline solution is added gradually over a period of $15 \mathrm{~min}$. The mixture is additionally stirred for $30 \mathrm{~min}$ followed by adjusting the temperature to the temperature described in Table 1.

A fully continuous system is tested by combining the exit flow of the continuous neutralization to the entrance of the continuous dispersion reactors, experiment numbers $3 \mathrm{~A}$ and 3B, Table 1 .

In order to pump the viscous prepolymer or NPP, the holding tank is pressurized with $\mathrm{N}_{2}$ gas. For each experiment, the applied pressure on this feed tank is measured with a pressure gauge and can be found in Supporting Information. The liquid exits through a bottom valve and is directed to the setup downstream. The tubings in the setup are stainless-steel $316 \mathrm{~L}$ and have an internal diameter of $4.6 \mathrm{~mm}$. The flow rate of the prepolymer or NPP is measured gravimetrically using a scale with continuous data logging $(\mathrm{KB} 10 \mathrm{~K} 0.05 \mathrm{~N}$, Kern) at the end of the setup and is manually controlled by the pressure on the feed tank. In experiments $2 \mathrm{C}$ and 2D, the NPP was pumped with a peristaltic pump (Watson \& Marlow, 120u). Water or alkaline solution is pumped pulse-free through piston pumps (Knauer, P4.1S) or a syringe pump (Teledyne ISCO D500) and is monitored using digital flowmeters (Mini CoriFlow, Bronkhorst). The dispersion is cooled either in flow by passing the liquid through a coiled tube at $20^{\circ} \mathrm{C}$ or by placing the sample vials in a water bath $\left(18^{\circ} \mathrm{C}\right)$.

Static Mixers and Y-Mixers. Figure 3 shows an overview of the Y-mixers used to mix the alkaline solution with the

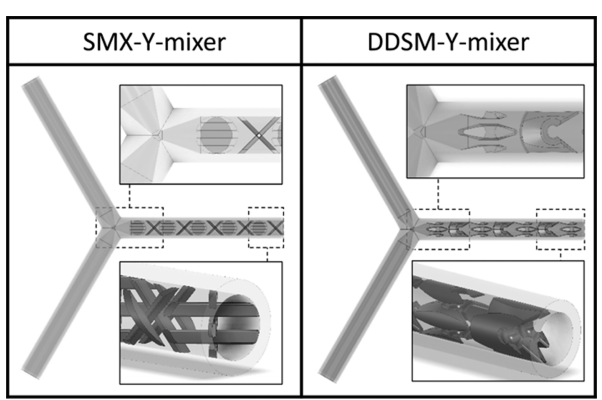

Figure 3. Overview of the Y-mixers used for mixing. Photograph courtesy of Tanguy Van Regemorter. Copyright 2020.

prepolymer in the continuous neutralization step and the NPP with water in the continuous dispersion step. The Y-mixers are 3D-printed in stainless steel (Custom made, Manetco) and have static mixing elements directly after the injection point. One Y-mixer has 10 static mixer elements similar to the SMX design and is referred to as the SMX-Y-mixer. The other one has seven static mixer elements that are based on the disruptive distributive static mixers (DDSM), referred to as the DDSMY-mixer. ${ }^{11}$ The injection point has an internal constriction of $1.5 \mathrm{~mm}$ internal diameter (ID), while the entrance and exit diameter is $4.35 \mathrm{~mm} \mathrm{ID}$, to minimize the pressure drop. In some experiments, the 3D-printed Y-mixer is used without the static mixers in them, referred to as the open Y-mixer; in these cases, the static mixers are placed in the water feed pipe, minimizing the pressure drop. After the Y-mixer, the liquid flows through a 13- or 20-element GX static mixer (ID 9.4 $\mathrm{mm}$, Stamixco). The cross-bar geometry of the SMX and GX is almost identical. The effective shear rate in laminar flow $\gamma\left(\mathrm{s}^{-1}\right)$ in these static mixers can be determined as follows ${ }^{12}$

$$
\gamma=\frac{V}{D} K_{\mathrm{G}}
$$

whereby $V$ is the superficial velocity of the liquid $(\mathrm{m} / \mathrm{s}), D$ is the pipe diameter $(\mathrm{m})$, and $K_{\mathrm{G}}$ is a dimensionless parameter specific to the static mixer geometry. For an SMX and GX mixer, this is $64 .^{13}$

Rotor-Stator Mixer. The RSM is used to study the dispersion step of the process (Figure 2, setup III, and Table 1 , experiments $2 \mathrm{C}$ and $2 \mathrm{D}$ ). For the study of the continuous dispersion, the neutralization of the prepolymer is carried out in batch at $75{ }^{\circ} \mathrm{C}$ as mentioned before. Before entering the 
RSM, the water and NPP are shortly mixed in a four-element Kenics mixer (ID $4.8 \mathrm{~mm}$ ). The RSM used is a pilot-scale Dispax Reactor IKA magic lab, with either the teeth design $2 \mathrm{G}$ module or the conical MK-mixing head. During dispersion in the RSM, a continuous recycle is used, whereby part of the exit flow is directed into the mixing head. Feed and exit flow rates are equal and independent of rotational speed of the RSM. For an RSM, the shear rate is based on the tip speed $U(U=\pi N D$, with $N$ being the rotational speed and $D$ being the rotor diameter), as follows

$$
\gamma=\frac{U}{\delta}
$$

whereby $\delta$ is the gap width between the rotor and the stator of the mixer.

Power Draw of the RSM. The power draw of both the $2 \mathrm{G}$ and $\mathrm{MK}$ modules is measured with water at different rotational speed settings through calorimetric measurements. The power draw is determined by

$$
P=\dot{m} c_{\mathrm{p}} \Delta T
$$

whereby $P$ is the power draw, $\dot{m}$ is the mass flow rate, $c_{\mathrm{p}}$ is the heat capacity of water, and $\Delta T$ is the temperature difference between the exit and entrance flow. The measurement of the temperature difference is sensitive to environmental temperature fluctuations. To avoid this interference, the jacket of the RSM and the entering fluid temperature are kept constant at $25{ }^{\circ} \mathrm{C}$, which allows isoperibolic conditions to be maintained. The additional temperature increase from the RSM motor housing temperature is corrected with the offset of the power draw $(P)$ as a function of the rotational speed $(N)$. The two temperature probes (Mettler Toledo EasyMax 102 Basic lab reactor) at the feed flow entrance and RSM exit measure every $2 \mathrm{~s}$ with a high reproducibility (standard deviation of $0.002{ }^{\circ} \mathrm{C}$ on 100 data points) until the temperature difference becomes constant. During calorimetric measurements, the RSM is operated with the entrance and exit channels placed at the same height to ensure that there is no liquid flow due to gravity when the rotor is not spinning.

\section{RESULTS AND DISCUSSION}

Static Mixers. Continuous Neutralization. The prepolymer is neutralized at different temperatures in the open Ymixer and the $13 \mathrm{GX}$ static mixers (setup I, Figure 2, and experiment 1A, Table 1), followed by dispersion in batch. The resulting average particle size and PDI are shown in Figure 4. Dispersions produced at neutralization temperatures of 50 and $65{ }^{\circ} \mathrm{C}$ were not stable, even at room temperature. The smallest particle size is obtained at $75{ }^{\circ} \mathrm{C}$, and at temperatures above 75 ${ }^{\circ} \mathrm{C}$, the particle size increases again. Samples taken at these temperatures $\left(\geq 75{ }^{\circ} \mathrm{C}\right)$ remained stable for 10 days at $60^{\circ} \mathrm{C}$. The zeta potential of these samples was lower than $-50 \mathrm{mV}$, indicating strong electrostatic repulsions. The influence of the neutralization temperature on the particle size and dispersion stability is attributed to the prepolymer viscosity during mixing. The prepolymer viscosity is extremely temperature-dependent (decreases from $121,000 \mathrm{mPa} \cdot \mathrm{s}$ at $40{ }^{\circ} \mathrm{C}$ to $640 \mathrm{mPa} \cdot \mathrm{s}$ at 100 ${ }^{\circ} \mathrm{C}$ ). At low temperature, the high viscosity of the prepolymer hinders the mixing process in the static mixers at a flow rate of $1 \mathrm{~kg} / \mathrm{h}$, leading to inadequate neutralization before dispersion. It is hypothesized that the imperfect mixing results in an uneven distribution of neutralized carboxyl groups, leading to

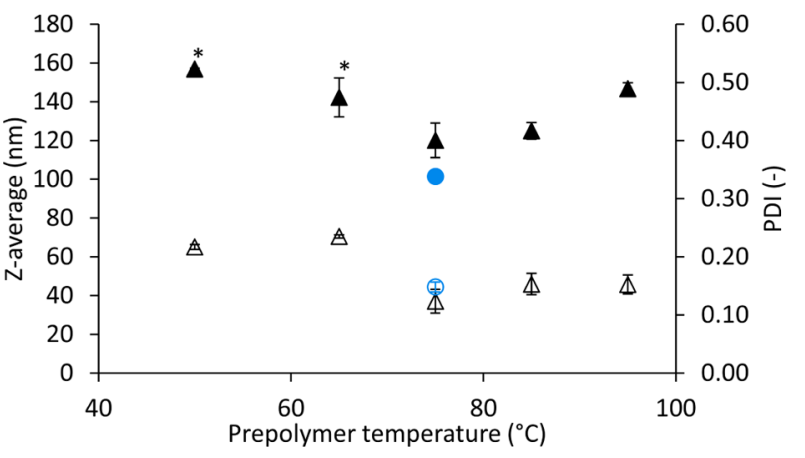

Figure 4. Influence of prepolymer temperature during the neutralization step in flow on the particle size and PDI of subsequent batch-made dispersions. ( $\Delta)$ Z-average $13 \mathrm{GX},(\triangle)$ PDI $13 \mathrm{GX}$, (blue - Z) -average DDSM-Y-mixer $+20 \mathrm{GX}$, and (blue O) PDI DDSM-Y-mixer +20 GX. Unstable samples are indicated by $(*)$. Error bars represent standard deviation $(n=2)$.

aggregation and sedimentation. As the temperature increases, the viscosity decreases, facilitating the mixing and thus the neutralization process. However, the slight increases in particle size at above $75{ }^{\circ} \mathrm{C}$ are poorly understood, but it is an observation that is also made in the results of the continuous dispersion.

The influence of mixing on the neutralization is studied by increasing the number of static mixers using the Y-mixer with DDSM static mixers and increasing the number of GX elements to 20 (Table 1, experiment 1B). This is also indicated in Figure 4. The subsequent dispersion yields smaller particles, indicating that the neutralization process is mixing-sensitive.

Continuous Dispersion. The influence of the NPP temperature on the continuous dispersion is shown in Figure 5 (setup

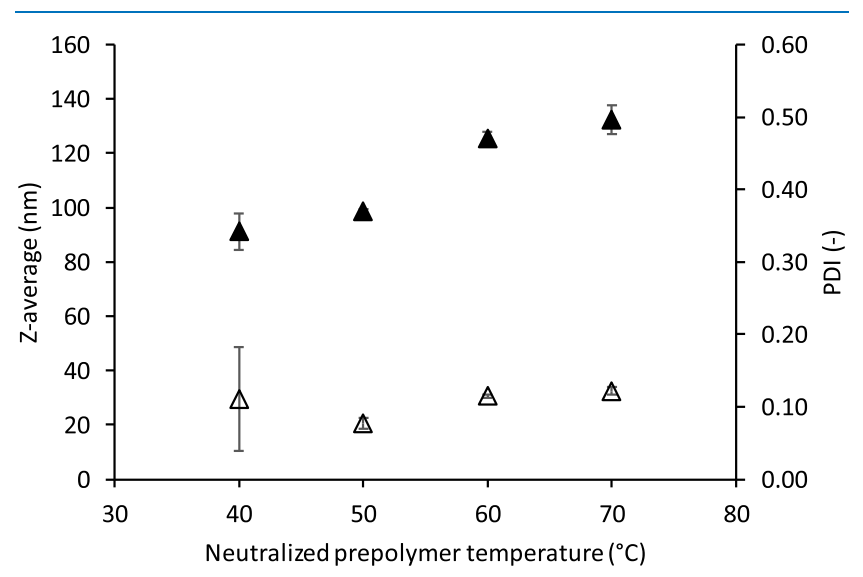

Figure 5. Influence of NPP temperature on the $(\boldsymbol{\Delta}) \mathrm{Z}$-average and $(\triangle)$ PDI of dispersions made in an open Y-injector and $13 \mathrm{GX}$ static mixers. Error bars represent standard deviation $(n=3)$.

II, Figure 2, and experiment 2A, Table 1). The average particle size of the dispersed particles is strongly dependent on the NPP temperature. A temperature increase results in an increase in particle size and PDI. All dispersions remained stable for 10 days at $60{ }^{\circ} \mathrm{C}$. A hypothesis is that a higher viscosity, due to the lower temperature during the dispersion step, results in the generation of smaller droplets. It has been shown that as the viscosity of the droplet increases, the elongation before rupture increases and more small satellite droplets are formed upon rupture. $^{14}$ 
To further improve the droplet disruption and decrease the particle size, the open Y-mixer is replaced with the SMX-Ymixer or DDSM-Y-mixer. Furthermore, the feed flow rate is varied from 1 to $4.5 \mathrm{~kg} / \mathrm{h}$ (setup I, Figure 2, and experiment $2 \mathrm{~B}$, Table 1). Higher feed flow rates also contribute to improved mixing efficiency by increased energy dissipation and turbulence in the static mixers. ${ }^{15}$ Compared to the open Ymixer, the implementation of the SMX or DDSM-Y-mixer reduces the average particle size by $8 \mathrm{~nm}$. A decrease in particle size is observed over a flow rate increase from 1 to $3 \mathrm{~kg} / \mathrm{h}$. At higher flow rates, the particle size stagnates. The PDI shows values below 0.1 , and all measured samples showed a zeta potential below $-40 \mathrm{mV}$, indicating a good dispersion stability (Figure 6).

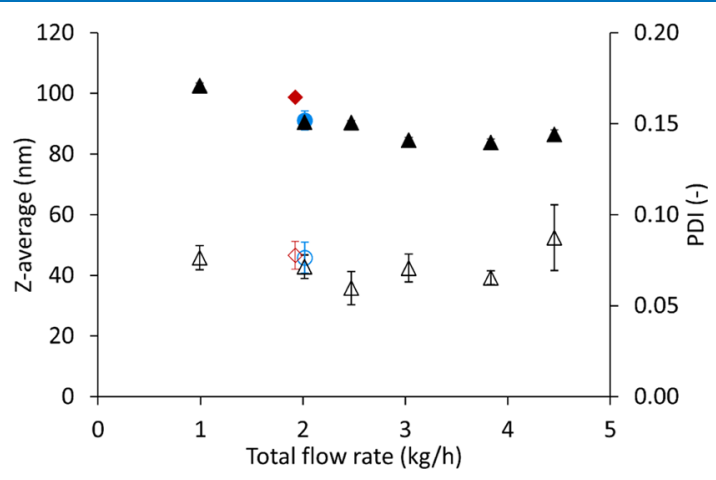

Figure 6. Influence of the total flow rate and static mixers in the Ymixer on the $\mathrm{Z}$-average and PDI during continuous dispersion production at a prepolymer temperature of $50{ }^{\circ} \mathrm{C}$. ( $(\boldsymbol{\Delta}) \mathrm{Z}$-average SMX-Y-mixer + 13 GX, $(\triangle)$ PDI SMX-Y-mixer + 13 GX, (blue $\bullet$ ) Zaverage DDSM-Y-mixer + 13 GX, (blue O) PDI DDSM-Y-mixer + 13 GX, (red $\diamond)$ Z-average open Y-mixer $+13 \mathrm{GX}$, and (red $\diamond)$ PDI open Y-mixer + 13 GX. Error bars represent the standard deviation $(n=3)$.

Rotor-Stator Mixers. Influence of the NPP Temperature. The influence of the feed flow rate and the temperature on the particle size and PDI during dispersion in an RSM is shown in Figure 7. In contrast to the dispersion experiments in the static mixers, no difference in particle size is seen for different NPP temperatures when using an inline RSM. Within an RSM, the

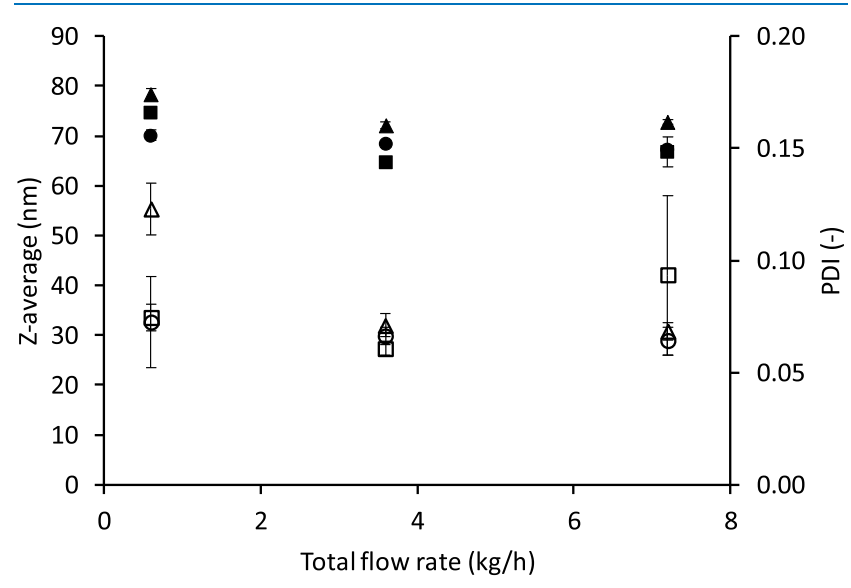

Figure 7. Influence of the feed flow rate and temperature on Zaverage and PDI of dispersions generated at $7400 \mathrm{rpm}$ in the inline RSM with module G2. Z-average at $(\boldsymbol{\square}) 60,(\boldsymbol{\Delta}) 75$, and $(\boldsymbol{\bullet}) 90^{\circ} \mathrm{C}$ and PDI at $(\square) 60,(\triangle) 75$, and $(\bigcirc) 90^{\circ} \mathrm{C}$. Error bars represent standard deviation $(n=3)$. shear forces exceed the shear forces inside the SMX mixer of the Y-piece, therefore reducing the particle size. The shear rate in the rotor-stator is $6.5 \times 10^{4} \mathrm{~s}^{-1}$ at $7400 \mathrm{rpm}$ (eq 2), while in the SMX ( $4.35 \mathrm{~mm}$ tube of the Y-piece at $2.0 \mathrm{~kg} / \mathrm{h}$, eq 1 ), the shear rate is 2 orders of magnitude smaller, $5.2 \times 10 \mathrm{~s}^{-1}$. In the setup with the $2 \mathrm{G}$ RSM, particle sizes below $80 \mathrm{~nm}$ and PDIs below 0.15 are achieved at 60,75 , and $90{ }^{\circ} \mathrm{C}$, and the samples were found to be stable at $60{ }^{\circ} \mathrm{C}$ for more than 10 days. The RSM thus allows operation at higher NPP temperatures, avoiding the need to cool the NPP after the neutralization (from 75 to $50{ }^{\circ} \mathrm{C}$ for static mixers). In addition, the reduced viscosity decreases the pressure drop in the system facilitating pumping. However, dispersions made at $50{ }^{\circ} \mathrm{C}$ and a total flow rate of $3.6 \mathrm{~kg} / \mathrm{min}$ were unstable at room temperature and samples exiting the RSM setup presented phase separation. This is attributed to inadequate mixing in the premixing in setup III (Figure 2), due to the high viscosity. The premixing is carried out in a Y-piece with a larger diameter (4 mm ID) compared to the Y-mixer used in the static mixer experiments (restriction of $1.5 \mathrm{~mm} \mathrm{ID)} \mathrm{and} \mathrm{only} \mathrm{a} \mathrm{short} \mathrm{Kenics} \mathrm{static} \mathrm{mixer}$ with four elements is used.

Influence of the Feed Flow Rate. Figure 7 shows the influence of the feed flow rate at different temperatures on the particle size and PDI during dispersion in an RSM. As the flow rate increases, the residence time in the mixing zone decreases, causing less shear forces acting on the dispersion. However, within a range of $0.6-7.2 \mathrm{~kg} / \mathrm{h}$ at a constant rotational speed of $7400 \mathrm{rpm}$, the Z-average values of the dispersions remain constant. Furthermore, PDIs remain below 0.15, indicating monodisperse dispersions. The particle size and PDI have likely reached a minimum, preventing further reduction. This is also interesting from a process engineering standpoint as it shows the robustness of the RSMs for a feed flow rate ranging from 1 to $7 \mathrm{~kg} / \mathrm{h}$.

Influence of Rotational Speed. Figure 8 shows the influence of the rotational speed on the particle size and PDI during dispersion in an RSM. Rotational speeds of 7400 and $15,000 \mathrm{rpm}$ are evaluated at different NPP temperatures, and the maximum rotational speed of $26,000 \mathrm{rpm}$ is tested at a prepolymer temperature of $90{ }^{\circ} \mathrm{C}$. The rotational speed range corresponds to shear rates of $0.68 \times 10^{5}$ to $2.3 \times 10^{5} \mathrm{~s}^{-1}$, eq 2 .

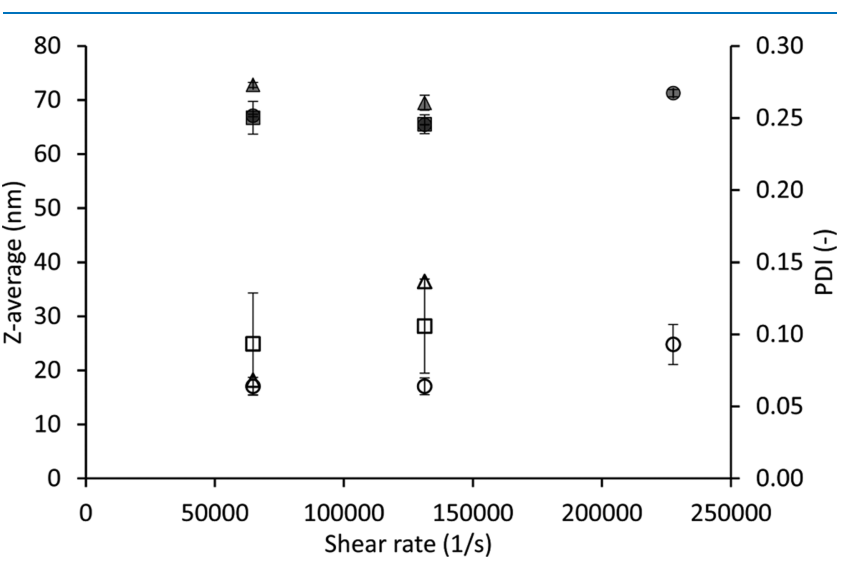

Figure 8. Influence of the shear rate on the Z-average and the PDI of dispersions generated in an inline RSM at three rotational speeds $(7400,15,000$, and $26,000 \mathrm{rpm})$, with module $2 \mathrm{G}$ at a feed flow rate of $7.2 \mathrm{~kg} / \mathrm{h}$. Z-average at $(\boldsymbol{\square}) 60,(\boldsymbol{\Delta}) 75$, and $(\bullet) 90^{\circ} \mathrm{C}$ and PDI at $(\square) 60,(\triangle) 75$, and $(O) 90{ }^{\circ} \mathrm{C}$. Error bars represent standard deviation $(n=3)$. 
Slightly lower particle sizes are observed for the prepolymer at $60{ }^{\circ} \mathrm{C}$ in comparison with 75 and $90{ }^{\circ} \mathrm{C}$. The average particle size remains constant at different rotational speeds. It is reasonable to think that a limiting plateau in particle size and polydispersity is reached as is also seen for different feed flow rates in Figure 7 . This is partly in agreement with the findings of Phongikaroon et al., who indicated that mechanical stirring does not influence the mean particle size for PU dispersions. ${ }^{4}$ Contrary to their findings, the current results also indicate that rotational speed does not affect the polydispersity. However, the particle sizes obtained in this study are 2 orders of magnitude smaller than the particles obtained by Phongicaroon, Calabrese, and Carpenter, and these PU dispersions are UV-PUDs.

Influence of Rotor-Stator Geometry. Figure 9 shows the power draw measurements in water for the MK module and

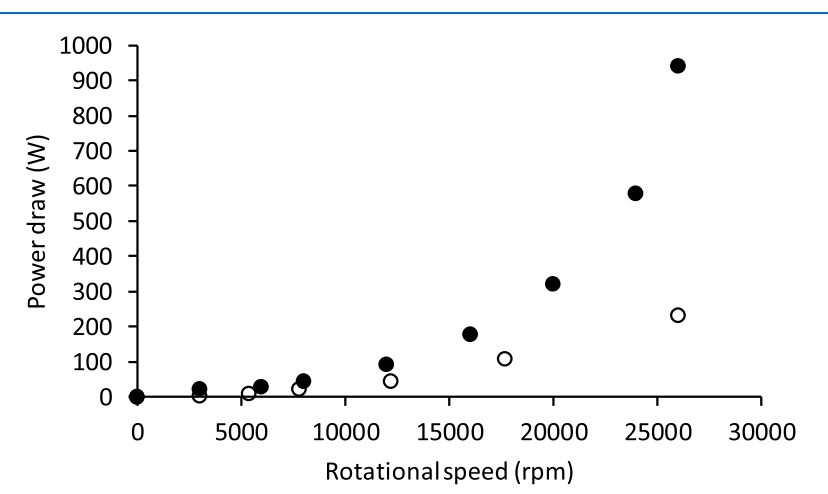

Figure 9. Power draw of the high-shear mixer at different rotational speeds and rotor-stator geometries, (O) G2 module and $(\bullet)$ MK module.

the G2 module which have a gap width of $0.16 \mathrm{~mm}$ and 0.180 , respectively. It is clear that the MK module is able to transfer more energy from the rotor to the liquid than the G2 rotorstator design.

The Z-average and PDI of the UV-PUDS obtained in the MK module and $2 \mathrm{G}$ module at $26,000 \mathrm{rpm}$ and a NPP temperature of $100{ }^{\circ} \mathrm{C}$ are $63.3 \pm 1.36 \mathrm{~nm}, \mathrm{PDI}=0.102 \pm$ 0.005 and $59.4 \pm 0.47 \mathrm{~nm}, \mathrm{PDI}=0.094 \pm 0.008$, respectively. Both systems deliver almost identical dispersion characteristics with Z-averages below $70 \mathrm{~nm}$ and PDIs close to 0.1 . Similar to the results of the rotational speed on the particle size, an increase in energy input shows no further reduction in particle size at this point. The difference in geometry also has no effect on the particle size distribution. Even though the power draw is higher in the MK module, both devices have a maximum tip speed of $40 \mathrm{~m} / \mathrm{s}$ at a rotational speed of $26,000 \mathrm{rpm}$ and a similar gap width, therefore delivering almost equal shear rates of $22 \times 10^{4}$ and $25 \times 10^{4} \mathrm{~s}^{-1}$.

Fully Continuous UV-PUD Process with Static Mixers and RSMs. For the continuous neutralization step, the DDSM-Ymixer and $20 \mathrm{GX}$ mixing elements are used at $75{ }^{\circ} \mathrm{C}$. For the continuous dispersion with static mixers, the NPP is precooled in-line to $50{ }^{\circ} \mathrm{C}$ and the SMX-Y-mixer is used in combination with $13 \mathrm{GX}$ mixers. Results are shown in Figure 10 for flow rates ranging from 2.4 to $5.2 \mathrm{~L} / \mathrm{h}$. All dispersions are stable at $60{ }^{\circ} \mathrm{C}$ for more than 10 days, and the zeta potential measurements were all below $-30 \mathrm{mV}$, indicating stable dispersions. Compared to the experiments with batch neutralization and continuous dispersion, slightly lower particle

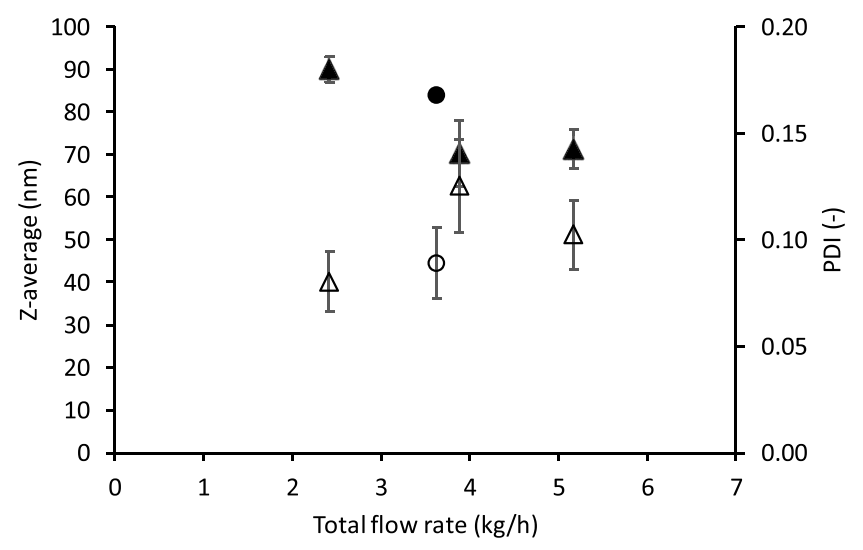

Figure 10. Influence of the total exit flow rate on the $\mathrm{Z}$-average and PDI of dispersions generated in the fully continuous setups, implementing the DDSM-Y-mixer and 20 GX mixers for the neutralization step and the SMX-Y-mixer and 13 GX mixers in the dispersion step or an RSM with recycle loop. ( $\mathbf{\Delta})$ Z-average static mixers, $(\triangle)$ PDI static mixers, $(\mathbf{\bullet}) \mathrm{Z}$-average RSM, and $(\mathrm{O})$ PDI RSM. Error bars represent standard deviation $(n \geq 3)$. The standard deviation is given using the error bars.

sizes are obtained in the fully continuous setup, which could be attributed to the improved mixing in both the neutralization and dispersion steps using static mixers. An important benefit of the continuous neutralization is the reduction of the process time compared to the batch. The batch neutralization requires long preparation times ( $>30 \mathrm{~min}$ ) including the time for gradual addition of the base solution and mixing to a homogeneous state. Due to the improved mixing of the viscous prepolymer, the neutralization process takes only $17 \mathrm{~s}$, at a dispersion production rate of $5.2 \mathrm{~kg} / \mathrm{h}$ in this small setup. Reproducibility is also tested by repetition of the fully continuous setup on three different days, resulting in a standard deviation of $3.3 \mathrm{~nm}$ on the Z-average, indicating the reproducibility of the process.

The results obtained for the continuous neutralization with static mixers and the continuous dispersion with the RSM indicate similar particle sizes to the process with only static mixers, as shown in Figure 10. The results imply that implementation of a high-shear mixer provides no advantage to the size reduction. With regard to energy expenditure, it is well known that the RSM requires more energy compared to static mixers. ${ }^{7}$ However, the RSM has shown to consistently deliver a particle size below $100 \mathrm{~nm}$, independent of the feed flow rate or temperature $\left(\geq 60{ }^{\circ} \mathrm{C}\right)$. Working at elevated temperatures is of interest for scale-up, with regard to reducing the viscosity and consequently reducing issues concerning pumping or pressure limits of the feed vessel. Furthermore, because the RSM acts as a pump, pressure drops in this setup were much lower compared to the static mixers. Pressure measurements, presented in Supporting Information, showed an exponential pressure increase for the static mixers at higher flow rates. This configuration with the neutralization in static mixers and the dispersion in an RSM is similar to the configuration that was used by Keyvani, who used two RSMs instead of one and also obtained dispersions, which were more stable than their batch equivalent. ${ }^{6}$ The particle size and PDI of the dispersions produced in this work are similar to their batch equivalent which is produced by adding the $\mathrm{NaOH}$ solution to the prepolymer stirred with an anchor blade at 75 ${ }^{\circ} \mathrm{C}$. The NPP is then slowly added to water stirred with a four- 
blade impeller at room temperature. The resulting dispersions also have a size of $60-90 \mu \mathrm{m}$, a PDI below 0.2 , a stability of at least 10 days at $60{ }^{\circ} \mathrm{C}$, and a zeta potential below $-30 \mathrm{mV}$.

These results demonstrate that static mixers are a viable option for both the neutralization and the dispersion of UVPUDs. Additionally, both RSMs and static mixers are applicable for the dispersion of UV-PUDs without noteworthy differences of the end product. It has been shown that the RSM is less dependent on process parameters such as temperature and feed rate and is thus more robust but requires more energy. These findings are a leap forward since there is, to the best of our knowledge, no research available on the continuous production of UV-PUDs and the research available for the continuous production of PUDs is rather limited. ${ }^{9}$ These results allow an advised transition from batch to continuous production.

\section{CONCLUSIONS}

UV-PUDs were successfully produced in continuous reactors. The neutralization is performed in a Y-mixer that is filled with 3D-printed DDSM mixing elements followed by GX static mixers, and the dispersion is carried out in a Y-mixer with 3Dprinted SMX mixing elements followed by GX static mixers or in an inline RSM. The temperature of the neutralization showed an optimum of $75{ }^{\circ} \mathrm{C}$ to reduce the particle size in the dispersion process. Furthermore, this process is shown to be mixing-sensitive whereby an increase in the number of static mixers for the neutralization leads to a reduction in particle size in the dispersion process. In situ neutralization also has the added benefit of reducing the process time of this predispersion step. The dispersion process in both the static mixer and the inline RSM showed Z-average values below 80 $\mathrm{nm}$ and the corresponding PDIs below 0.1. Within the static mixer, the particle size showed great dependency on the NPP temperature. Higher temperatures result in larger particles and PDIs. For the high-shear mixers, limited influence of prepolymer temperature is observed. With regard to the energy input for dispersion, the effects of the feed flow rate on the static mixers and shear rate in the RSM showed a limited influence in reducing particle size. To further reduce the particle size below the plateau of $60-70 \mathrm{~nm}$ reached in this study, other approaches focusing on the polymer chemistry (number of neutralized groups and neutralization degree) are needed..

\section{ASSOCIATED CONTENT}

\section{(s) Supporting Information}

The Supporting Information is available free of charge at https://pubs.acs.org/doi/10.1021/acsomega.1c01525.

Pressure drop and zeta potentials in different experiments (PDF)

\section{AUTHOR INFORMATION}

\section{Corresponding Authors}

Arne Vancleef - Department of Chemical Engineering, $K U$ Leuven, B-3590 Diepenbeek, Belgium; 이이.org/00000001-6286-649X; Email: arne.vancleef@kuleuven.be

Leen C. J. Thomassen - Department of Chemical Engineering, KU Leuven, B-3590 Diepenbeek, Belgium; Email: leen.thomassen@kuleuven.be

\section{Authors}

Sven R. L. Gobert - Department of Chemical Engineering, KU Leuven, B-3590 Diepenbeek, Belgium; (1) orcid.org/ 0000-0001-6595-9835

Seppe Clercx - Department of Chemical Engineering, $\mathrm{KU}$ Leuven, B-3590 Diepenbeek, Belgium

Leen Braeken - Department of Chemical Engineering, KU Leuven, B-3590 Diepenbeek, Belgium

Complete contact information is available at:

https://pubs.acs.org/10.1021/acsomega.1c01525

\section{Author Contributions}

${ }^{\dagger}$ Equal contributors.

\section{Funding}

This research was funded by the Agency for Innovation and Entrepreneurship (VLAIO) and Catalisti grant number PIF HBC.2017.0442.

\section{Notes}

The authors declare no competing financial interest.

\section{ACKNOWLEDGMENTS}

The authors acknowledge the R\&D division of Allnex for its support.

\section{REFERENCES}

(1) Kim, B. K. Aqueous Polyurethane Dispersions. Colloid Polym. Sci. 1996, 274, 599-611.

(2) Tennebroek, R.; van der Hoeven-van Casteren, I.; Swaans, R.; van der Slot, S.; Stals, P. J.; Tuijtelaars, B.; Koning, C. Water-based polyurethane dispersions. Polym. Int. 2019, 68, 832-842.

(3) Zhang, J.; Ren, H.; Chen, P.; Zhang, Z.; Hu, C. Preparation and Properties of Waterborne Polyurethane with Star-Shaped Hyperbranched Structure. Polymer 2019, 180, 121690.

(4) Phongikaroon, S.; Calabrese, R. V.; Carpenter, K. Elucidation of Polyurethane Dispersions in a Batch Rotor-Stator Mixer. J. Coating Technol. Res. 2004, 1, 329-335.

(5) Dieterich, D. Aqueous emulsions, dispersions and solutions of polyurethanes; synthesis and properties. Prog. Org. Coat. 1981, 9, 281-340.

(6) Keyvani, M. Improved Polyurethane Dispersion Stability via Continuous Process. Adv. Polym. Technol. 2003, 22, 218-224.

(7) El-Jaby, U.; Cunningham, M.; McKenna, T. F. L. Comparison of Emulsification Devices for the Production of Miniemulsions. Ind. Eng. Chem. Res. 2009, 48, 10147-10151.

(8) Håkansson, A.; Arlov, D.; Carlsson, F.; Innings, F. Hydrodynamic Difference between Inline and Batch Operation of a RotorStator Mixer Head - A CFD Approach. Can. J. Chem. Eng. 2017, 95, $806-816$.

(9) Liu, X.; Hong, W.; Chen, X. Continuous Production of WaterBorne Polyurethanes: A Review. Polymers 2020, 12, 2875.

(10) Joseph, E.; Singhvi, G. Multifunctional Nanocrystals for Cancer Therapy: A Potential Nanocarrier. Nanomaterials for Drug Delivery and Therapy; Elsevier Inc., 2019.

(11) Gramann, P.; Davis, B.; Osswald, T.; Rauwendaal, C. A New Dispersive and Distributive Static Mixer for the Compounding of Highly Viscous Materials. SPE/ANTEC 1999 Proceedings; CRC Press, 1999.

(12) Paul, E. L.; Atiemo-obeng, V. A.; Kresta, S. M. Handbook of Industrial Mixing; John Wiley \& Sons, Inc.: New Jersey, 2004.

(13) Streiff, F. A.; Jaffar, S.; Schneider, G. Design and Application of Motionless Mixer Technology. Proceeding of ISMIP3; Osaka, 1999; pp 107-114.

(14) Tcholakova, S.; Vankova, N.; Denkov, N. D.; Danner, T. Emulsification in turbulent flow: J. Colloid Interface Sci. 2007, 310, 570-589. 
(15) Farzi, G. A.; Rezazadeh, N.; Nejad, A. P.; Farzi, G. A.; Rezazadeh, N.; Nejad, A. P. Droplet Formation Study in Emulsification Process by KSM Using a Novel In Situ Visualization System. J. Dispersion Sci. Technol. 2016, 37, 575-581. 